\title{
Impact of Remote Consultations on Antibiotic Prescribing in Primary Health Care: Systematic Review
}

Seung Min Han ${ }^{1}$, BSc; Geva Greenfield ${ }^{2}$, PhD; Azeem Majeed ${ }^{2}$, MB, Bch, MD, FRCP, FRCGP, FFPH; Benedict Hayhoe $^{2}$, BSc, MBBS, LLM, MD, DRCOG, DPMSA, MRCGP, FHEA, FFCI

\footnotetext{
${ }^{1}$ School of Public Health, Imperial College London, London, United Kingdom

${ }^{2}$ Department of Primary Care and Public Health, School of Public Health, Imperial College London, London, United Kingdom
}

Corresponding Author:

Geva Greenfield, PhD

Department of Primary Care and Public Health

School of Public Health

Imperial College London

314 The Reynolds Building

St Dunstan's Road

London, W6 8RP

United Kingdom

Phone: 4402075948595

Email: g.greenfield@ic.ac.uk

\section{Abstract}

Background: There has been growing international interest in performing remote consultations in primary care, particularly amidst the current COVID-19 pandemic. Despite this, the evidence surrounding the safety of remote consultations is inconclusive. The appropriateness of antibiotic prescribing in remote consultations is an important aspect of patient safety that needs to be addressed.

Objective: This study aimed to summarize evidence on the impact of remote consultation in primary care with regard to antibiotic prescribing.

Methods: Searches were conducted in MEDLINE, Embase, HMIC, PsycINFO, and CINAHL for literature published since the databases' inception to February 2020. Peer-reviewed studies conducted in primary health care settings were included. All remote consultation types were considered, and studies were required to report any quantitative measure of antibiotic prescribing to be included in this systematic review. Studies were excluded if there were no comparison groups (face-to-face consultations).

Results: In total, 12 studies were identified. Of these, 4 studies reported higher antibiotic-prescribing rates, 5 studies reported lower antibiotic-prescribing rates, and 3 studies reported similar antibiotic-prescribing rates in remote consultations compared with face-to-face consultations. Guideline-concordant prescribing was not significantly different between remote and face-to-face consultations for patients with sinusitis, but conflicting results were found for patients with acute respiratory infections. Mixed evidence was found for follow-up visit rates after remote and face-to-face consultations.

Conclusions: There is insufficient evidence to confidently conclude that remote consulting has a significant impact on antibiotic prescribing in primary care. However, studies indicating higher prescribing rates in remote consultations than in face-to-face consultations are a concern. Further, well-conducted studies are needed to inform safe and appropriate implementation of remote consulting to ensure that there is no unintended impact on antimicrobial resistance.

(J Med Internet Res 2020;22(11):e23482) doi: 10.2196/23482

\section{KEYWORDS}

remote consultations; antibiotic; primary health care; systematic review; consultation; telehealth; COVID-19; safety; prescription

\section{Introduction}

Recent years have seen unsustainable workload increases in primary health care. Remote consultations, in which primary care professionals (PCPs) communicate with patients by telephone or internet as an alternative to face-to-face consultations, have been implemented to maximize the efficiency of primary care services and meet patient demand 
for greater and more convenient access to primary health care advice [1]. Over 90 countries have been reported to be already delivering health care services over the telephone in 2016 [1], and remote consultations have been playing a substantial role in the health care response to the current COVID-19 pandemic by supporting continued access to services with minimized risk of disease transmission $[2,3]$.

The increasingly commonplace nature of remote consulting in primary care notwithstanding, there remains much uncertainty regarding the safety and effectiveness of remote consultations [4,5]. For example, PCPs are more likely to prescribe medications in remote consultations than in face-to-face settings $[6,7]$. In particular, antibiotic prescribing behavior can be influenced by nonclinical factors that are unique to remote consultations, such as the inability to physically examine the patient [8]. The overprescribing of antibiotics drives antimicrobial resistance, which is a global concern with consequent impact on patients and health systems, especially primary health care. Over $80 \%$ of all antibiotic prescriptions are dispensed by primary care in the United Kingdom [9-11].

Evidence for the impact of remote consultations on antibiotic prescribing in primary care is currently unclear. Given the growing international adoption of remote consultations into primary care, which has intensified during the ongoing COVID-19 pandemic, any impact of remote consultations on antibiotic prescribing needs to be properly understood. This study aims to summarize the impact of remote consultations on primary care antibiotic prescribing.

\section{Methods}

This systematic review was conducted following the PRISMA (Preferred Reporting Items for Systematic Reviews and Meta-Analyses) guidelines (Multimedia Appendix 1) [12].

\section{Eligibility Criteria}

Included studies were required to be conducted in primary health care settings only. Any type of remote consultations between patient and PCP were accepted as the intervention. For comparison, any form of face-to-face consultation in primary health care was accepted. The primary outcomes of interest were quantitative measures of antibiotic prescriptions in remote consultations. The proportion of guideline-concordant antibiotic prescriptions and follow-up visit rates were considered secondary outcomes. Studies assessing the prescribing rates of any drug without providing data on antibiotics were excluded.

We included peer-reviewed primary research articles written in English in this systematic review. Studies could be observational or randomized controlled trials (RCTs), but conference abstracts, editorials, and qualitative studies that did not provide measures of antibiotic prescribing frequency were excluded. We did not exclude literature based on publication date so that we could capture all available literature.

\section{Search Strategy}

A scoping review was conducted to establish the search terms. A research librarian was consulted for guidance regarding the search strategy. An initial list of search terms was developed and applied to MEDLINE and Embase to check the relevance of results, and reference lists from several relevant studies and similar reviews were manually searched to expand the search terms. Search strings were then amended according to the subject headings for each database. The final list of search terms for each database is presented in Multimedia Appendix 2.

\section{Study Selection}

A search was conducted on February 14, 2020, in 5 electronic databases: MEDLINE, Embase, PsycINFO, HMIC, and CINAHL. We had 3 reviewers independently screen studies for inclusion. One reviewer ( $\mathrm{SH}$ ) screened all titles and abstracts, and $\mathrm{BH}$ and GG each screened $50 \%$ of the titles and abstracts. The same approach was subsequently performed for full-text screening. Discrepancies were resolved through discussion between the reviewers. The studies were stored using Mendeley reference management software, and duplicates were removed through Mendeley's deduplication function and manual searching.

\section{Data Extraction}

Study characteristics and outcomes were extracted using a Microsoft Excel spreadsheet. The data extraction form was created in advance and finalized after piloting it on two studies. Data from included studies were extracted by SH.

\section{Risk of Bias}

The National Heart, Lung, and Blood Institute tool [13] was used to assess observational studies, and the Cochrane risk of bias tool [14] was applied to RCTs. The reviewers carefully considered the efforts required to minimize the risk of bias for each domain and ensured that the overall quality rating of each paper was not purely based on the tally of each appraisal form. SH assessed the quality of all papers and BH and GG each assessed half of the studies independently. Conflicting assessments and overall risk of bias were determined through discussion.

\section{Analysis}

Results were presented as reported by the original authors of each study, and similar outcomes that were reported frequently were grouped together for analysis. The results were presented through narrative synthesis [15]. The included studies were considered too heterogeneous in terms of study population, type of consultation, and outcome definitions for meta-analysis.

\section{Results}

\section{Study Selection}

Our electronic database search yielded 2427 results, of which 12 studies were included in this review (Figure 1) [12]. We found 2 papers $[16,17]$ that were part of the same study with identical study periods and participants, so the results most relevant to this systematic review were reported. 
Figure 1. Literature search flow chart adapted from PRISMA (Preferred Reporting Items for Systematic Reviews and Meta-Analyses) flow chart.

\section{PRISMA 2009 Flow Diagram}

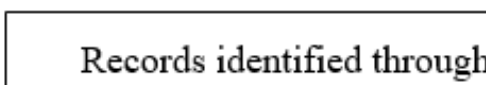
database searching $(n=2427)$

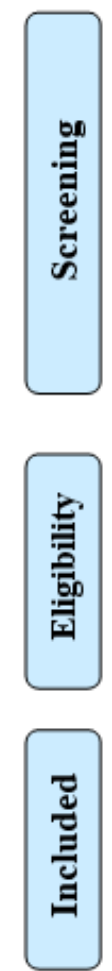

Records after duplicates removed $(\mathrm{n}=1554)$
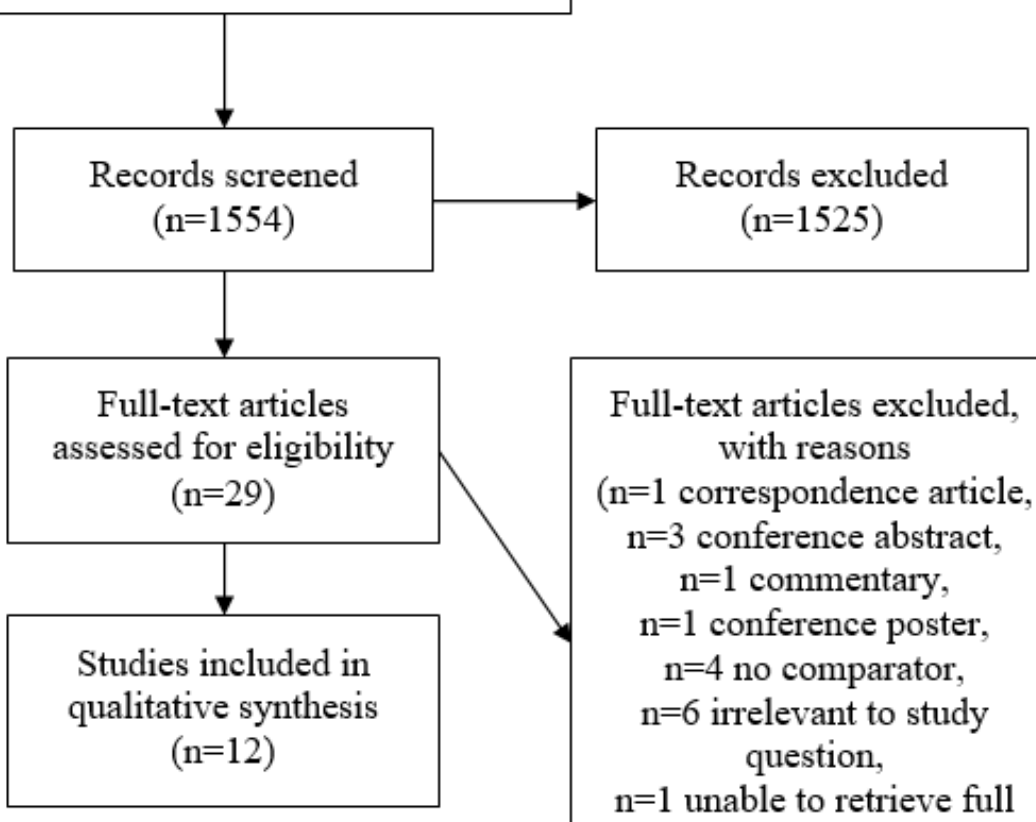

Full-text articles excluded, with reasons ( $\mathrm{n}=1$ correspondence article, $\mathrm{n}=3$ conference abstract, $\mathrm{n}=1$ commentary, $\mathrm{n}=1$ conference poster, $\mathrm{n}=4$ no comparator, $\mathrm{n}=6$ irrelevant to study question, $n=1$ unable to retrieve full text)

\section{Characteristics of Included Studies}

The characteristics and results of the 12 studies are summarized in Tables 1 and 2 [16-27]. Of these 12 studies, 9 were conducted in the United States [18,19,22-27], 2 were conducted in Denmark [16,17], and 1 was conducted in Norway [20]. Most studies (11/12) [16-20,22-27] had a cohort design, including 1 RCT [21]. 
Table 1. Summary of study characteristics.

\begin{tabular}{|c|c|c|c|c|c|}
\hline Study (author, year) & Country & Setting & Study design & Population & Remote consultation type \\
\hline $\begin{array}{l}\text { Rokstad and } \\
\text { Straand, } 1997 \text { [20] }\end{array}$ & Norway & $\begin{array}{l}\text { Primary care prac- } \\
\text { tices }\end{array}$ & Prospective cohort & All registered patients & $\begin{array}{l}\text { Telephone, letter, or } \\
\text { through a messenger } \\
\text { (mixed) }\end{array}$ \\
\hline $\begin{array}{l}\text { McKinstry et al, } \\
2002[21]\end{array}$ & Scotland & $\begin{array}{l}\text { Primary care prac- } \\
\text { tices }\end{array}$ & $\begin{array}{l}\text { Randomized con- } \\
\text { trolled trial }\end{array}$ & $\begin{array}{l}\text { All patients that phoned for a } \\
\text { same-day appointment }\end{array}$ & Telephone \\
\hline $\begin{array}{l}\text { Huibers et } \mathrm{al}^{\mathrm{a}}, 2014 \\
{[16]}\end{array}$ & Denmark & $\begin{array}{l}\text { Out-of-hours prima- } \\
\text { ry care contacts }\end{array}$ & Retrospective cohort & All registered patients & Telephone \\
\hline $\begin{array}{l}\text { Ewen et al, } 2015 \\
\text { [23] }\end{array}$ & United States & $\begin{array}{l}\text { Primary care prac- } \\
\text { tices }\end{array}$ & Retrospective cohort & All registered patients & Telephone \\
\hline $\begin{array}{l}\text { Christensen et } \mathrm{al}^{\mathrm{a}} \text {, } \\
2016 \text { [17] }\end{array}$ & Denmark & $\begin{array}{l}\text { Out-of-hours prima- } \\
\text { ry care contacts }\end{array}$ & Retrospective cohort & All registered patients & Telephone \\
\hline Shi et al, 2018 [25] & United States $^{b}$ & $\begin{array}{l}\text { Primary care prac- } \\
\text { tices }\end{array}$ & Retrospective cohort & Adults aged $18-64$ years & $\begin{array}{l}\text { Audio and audio-visual } \\
\text { conferencing (mixed) }\end{array}$ \\
\hline Ray et al, 2019 [27] & United States $^{\mathrm{b}}$ & $\begin{array}{l}\text { Primary care prac- } \\
\text { tices }\end{array}$ & Retrospective cohort & Children aged $0-17$ years & $\begin{array}{l}\text { Audio-only or audio-video } \\
\text { conferencing (mixed) }\end{array}$ \\
\hline $\begin{array}{l}\text { Murray et al, } 2019 \\
{[18]}\end{array}$ & United States & $\begin{array}{l}\text { Primary care prac- } \\
\text { tices or retail clinics }\end{array}$ & Retrospective cohort & Women aged $18-65$ years & $\begin{array}{l}\text { Telephone and text-based } \\
\text { e-visit }\end{array}$ \\
\hline $\begin{array}{l}\text { Johnson et al, } 2019 \\
\text { [26] }\end{array}$ & United States & $\begin{array}{l}\text { Primary care prac- } \\
\text { tices }\end{array}$ & Retrospective cohort & Adults aged $\geq 18$ years & Text-based e-visit \\
\hline
\end{tabular}

${ }^{\mathrm{a}}$ Articles published on the same study.

${ }^{\mathrm{b}}$ The data were sourced from national health insurance companies. Therefore, no specific setting was recorded. 
Table 2. Main findings of studies.

\begin{tabular}{lll}
\hline Indication for antibiotics, study (author, year) & $\begin{array}{l}\text { Remote consulta- } \\
\text { tions, N }\end{array}$ & $\begin{array}{l}\text { Face-to-face consul- Outcome measures } \\
\text { tations (control), N }\end{array}$
\end{tabular}

Antibiotic-prescribing rate higher in remote consultations

Mehrotra et al, 2012 [22]

Sinusitis

Urinary tract infection

99

Uscher-Pines et al, 2016 [24]

Uncomplicated acute bronchitis

168

7342

Ray et al, 2019 [27]

Acute respiratory infection

4604

38408

Penza et al ${ }^{\mathrm{c}}, 2020$ [19]

Conjunctivitis

101

202

Antibiotic-prescribing rate lower in remote consultations

Rokstad and Straand, 1997 [20]

Not specified

24983

42202

Huibers et al ${ }^{d}, 2014$ [16]

Not specified

382748

180032

\section{Shi et al, 2018 [25]}

Acute respiratory infection

38839

942163

Johnson et al, 2019 [26]

Sinusitis

175

175

Antibiotic-prescribing Intervention: 99\%, control: rate $^{\mathrm{a}}$ 94\% $(P<.001)$

Antibiotic-prescribing Intervention: 99\%, control: rate $^{\mathrm{a}}$ $49 \%(P<.001)$

Antibiotic-avoidance rate $^{\mathrm{b}}$

Intervention: $16.7 \%$, control: $27.9 \%(P<.01)$

Antibiotic-prescribing Intervention: 52\%, control: rate $^{\mathrm{a}}$ $31 \%(P<.001)$

Antibiotic-prescribing Intervention: 41.6\%, control: rate $^{\mathrm{a}}$ during telephone $19.8 \%(P<.0001)$ consultations

Proportion of prescriptions and antibiotics prescriptions made through each consultation type

Antibiotic-prescribing rate $^{\mathrm{a}}$

tervention: $26.1 \%(95 \%$ CI 25.9-26.3)

Control: $10.7 \%(95 \%$ CI 10.6 10.8)

Proportion of antibiotics prescriptions out of all prescriptions

Antibiotic-prescribing rate ${ }^{\mathrm{a}}$ lower in intervention*

Intervention: $43.5 \%$ of all prescriptions; $7.8 \%$ of remote prescriptions were antibiotics

Control: $56.6 \%$ of all prescriptions; $17.8 \%$ of face-to-face prescriptions were antibiotics

$12.4 \%$ of all antibiotics prescriptions made through telephone (6617 telephone consultations and 27,487 office consultations; 63,418 antibiotics were prescribed during 61,707 consultations to 31,302 individuals)*

Antibiotic-prescribing Intervention: 52\%, control: rate $^{\mathrm{a}}$ $53 \%(P<.01)$

Antibiotic-prescribing Intervention: $68.6 \%$, control: rate $^{\mathrm{a}}$ 


\begin{tabular}{|c|c|c|c|c|}
\hline Indication for antibiotics, study (author, year) & $\begin{array}{l}\text { Remote consulta- } \\
\text { tions, } \mathrm{N}\end{array}$ & $\begin{array}{l}\text { Face-to-face consul- } \\
\text { tations (control), N }\end{array}$ & Outcome measures & Results \\
\hline Not specified & 187 & 181 & $\begin{array}{l}\text { Antibiotic-prescribing } \\
\text { rate }^{\mathrm{a}}\end{array}$ & $\begin{array}{l}\text { Intervention: } 19.3 \% \text {, control: } \\
16.0 \% \text {; difference: }-3.3 \%(95 \% \\
\text { CI }-11.1 \% \text { to } 4.5 \%)\end{array}$ \\
\hline
\end{tabular}

Murray et al, 2019 [18]

Urinary tract infection

Urinary tract infection

150

150

150

150

Penza et al ${ }^{\mathrm{c}}, 2020$ [19]

Conjunctivitis
101
202 $\begin{array}{ll}\text { Antibiotic-prescribing } & \text { Intervention: } 81 \%, \text { control: } \\ \text { rate }^{\mathrm{a}} \text { in telephone } & 83 \%(P=.76) \\ \text { consultations } & \end{array}$

Antibiotic-prescribing Intervention: $81 \%$, control: rate $^{\mathrm{a}}$ from text-based $83 \%(P=.65)$ e-visits
Antibiotic-prescribing Intervention: $25.7 \%$, control: rate $^{\mathrm{a}}$ from text-based $19.8 \%(P=.24)$ e-visits

\footnotetext{
${ }^{a}$ Antibiotic-prescribing rate: percentage of consultations that resulted in antibiotic management per consultation type.

${ }^{\mathrm{b}}$ Antibiotic-avoidance rate: percentage of patients that did not receive antibiotics for uncomplicated acute bronchitis, as they had no clinical indication.

${ }^{\mathrm{c}}$ Results of the same study for different populations reported separately.

${ }^{d}[16]$ and [17] are articles published on the same study. The results from the Huibers et al [16] study are reported in this table.

${ }^{e}$ Number of remote consultations and face-to-face consultations in this study was not available. The number of consultations altogether has been reported instead.

* $P$ values or confidence intervals not reported in the original studies.
}

The study population varied in age and sex depending on whether the study investigated specific conditions. Of 2 studies analyzing antibiotic prescribing for urinary tract infection (UTI) [18,22], 1 limited their participants to adult women [18]. Additionally, 2 studies focused only on children with conjunctivitis or acute respiratory infection [19,27].

A majority of studies (7/12) employed telephone consultations, text-based e-visits, or both as their intervention [17-19,21-23,26]. Moreover, 2 studies [25,27] grouped audio-only and video consultations for their intervention, and another study [20] grouped all consultations made through telephone, letters, or messengers. The control arm was face-to-face primary care clinic consultations for all except 2 studies. The Penza et al [19] control group was made up of walk-in retail clinic patients, and the controls for Murray et al [18] were retail clinic and primary care practice patients. Furthermore, while most consultations were evaluated by primary care physicians, telephone consultations in the Penza et al [19] and Murray et al [18] studies were evaluated by registered nurses. Text-based e-visits were assessed by advanced practice providers in the Murray et al [18] study and nurse practitioners in the Penza et al [19] study.

\section{Risk of Bias Within Studies}

The quality assessment is presented in Multimedia Appendix 3. The quality of studies was generally fair, with 7 moderate-quality studies, including the RCT, and 5 observational studies that were considered high quality. All studies had clearly defined their objectives, study population, and exposure and outcome measures. However, only 2 studies provided sample size justifications or power calculations [17,26]. Additionally, 4 studies lacked adjustment for any confounding factors
$[16,18,20,23]$. The RCT described adequate randomization, but lacked blinding [21]. However, we did not consider this to significantly impact the quality, since blinding to consultation type is rarely feasible.

\section{Impact of Remote Consultations on Antibiotic Prescribing Behavior}

The main findings are outlined in Table 2, with confidence intervals and $P$ values reported where available. In most studies, the impact of remote consultation on antibiotic prescribing was measured by the percentage of consultations with one or more antibiotic prescriptions for each type of consultation. This measure has been uniformly referred to as the antibiotic-prescribing rate in this review, following the practice in the included studies.

We found 3 studies that reported the antibiotic-prescribing rate to be higher in remote settings than face-to-face consultations $[19,22,27]$. The difference in prescribing rate ranged from $5 \%$ $(n=201)$ to $50 \% \quad(n=5165)$ [22]. Penza et al found this relationship for both telephone and text-based e-visits, but only the difference in telephone consultations was statistically significant [19]. Another study concluded that fewer antibiotics were avoided for bronchitis patients consulting over the phone; patients were more likely to receive an antibiotic for the same condition when consulting remotely [24].

We also found 3 cohort studies that reported patients were more likely to be prescribed an antibiotic through face-to-face consultations $[16,25,26]$. The differences in prescribing rates were generally smaller in these studies; 1 study found a $1 \%$ difference $(n=1,336,867)$ [25], and the largest difference observed was $25.7 \% \quad(n=350)$ [26]. Additionally, 2 moderate-quality studies, an RCT and a retrospective cohort 
study, noted no significant difference in prescribing rate between the different settings [18,21].

It was difficult to compare 2 studies with the other included studies due to differences in outcome measures; neither included a direct estimate of antibiotic prescribing. Rokstad and Straand [20] and Ewen et al [23] claimed that antibiotic-prescribing rate was higher in face-to-face consultations based on the percentage of antibiotic prescriptions issued through each consultation type. However, their results do not consider multiple prescriptions made in one consultation. Therefore, their claims should be considered with caution.

Clinicians may be more likely to prescribe antibiotics for UTI in remote consultations. Of 2 studies assessing patients with suspected or confirmed UTI, 1 study found higher antibiotic-prescribing rates in remote consultations [22]. Mehrotra et al [22] concluded that PCPs were less likely to order a UTI-relevant test in face-to-face consultations (did not order: $8 \%$, did order: $51 \%$; $\mathrm{P}<.01$ ), but more likely to prescribe an antibiotic for UTI in remote consultations. Another moderate-quality study found no significant difference in antibiotic-prescribing rate for patients with UTI [18]. However, the researchers hypothesized that their results could have been affected by differences in face-to-face settings; face-to-face consultations in the Mehrotra et al [22] study were performed in retail clinics where there may have been less continuity of care than primary care practices.

Results for respiratory infections were mixed. In 3 studies, of which 2 were of high quality, researchers found higher antibiotic-prescribing rates in remote consultations than in direct PCP consultations [22,24,27]. However, 2 other high-quality studies noted lower antibiotic-prescribing rates for patients consulting remotely $[25,26]$.

\section{Impact of Remote Consultations on Guideline-Concordant Prescribing Rate}

We found 4 observational studies that reported guideline-concordant prescribing rates or guideline-recommended prescribing rates, which measured the appropriateness of the prescriptions against local or national guidelines [22,25-27] (Table 2). All studies were from the United States and investigated populations with a confirmed diagnosis of sinusitis [22,26], UTI [22], or acute respiratory infection [25,27].

In contrast to the findings for antibiotic-prescribing rate, the guideline-concordant antibiotic management for sinusitis and patients with UTI revealed no significant difference between remote and face-to-face consultations [22,26]. However, conflicting results were observed for patients with acute respiratory infection $[25,27]$.

\section{Impact of Remote Consultations on Follow-Up Visits}

We found 5 US-based retrospective cohort studies that investigated follow-up visit rates after initial consultation for the same presentation $[18,19,22,25,26]$. Of these 5 studies, 3 found that patients who were seen remotely were more likely to have another follow-up visit than those who attended face-to-face consultations $[19,25,26]$. Shi et al [25] found this to be true for those who followed up within 2-21 days after their first visit. Results from the Penza et al [19] study indicated higher follow-up rates in both e-visits and telephone consultations than in face-to-face consultations 7 days after the initial visit. Johnson et al [26] found this relationship to be true for text-based e-visits relating to sinusitis in the subsequent 24 hours and 30 days after the initial consultation, but found no difference in follow-up consultations at 7 days after the initial consultation. However, Murray et al [18] and Mehrotra et al [22] found no significant difference in follow-up visit rates between the consultation types within the following 3 weeks and 30 days after the initial consultation, respectively. Further, Murray et al [18] found no significant difference in antibiotic-prescribing rates in the initial consultation for patients who were followed up with.

\section{Discussion}

\section{Principal Results}

To our knowledge, this is the first systematic review to examine how antibiotic prescribing is affected by remote consultation in primary care. This review of moderate- to high-quality studies found that evidence regarding the impact of remote consultations on antibiotic prescribing was mixed. Studies reporting higher antibiotic-prescribing rates in remote consultations than in face-to-face consultations were generally of better quality. However, the inconsistency of results and the small number of studies make it difficult to draw strong conclusions for the effect of remote consultations on antibiotic prescribing.

The studies examining specific indications for antibiotics suggested that antibiotic-prescribing rates for patients with UTI in remote consultations was higher than in face-to-face consultations, but 1 study did not find any difference [18]. Guideline-concordant prescribing rates for patients with UTI or sinusitis were not significantly changed by remote consultations. However, there was mixed evidence regarding whether remote consultations were more likely to be followed up with another consultation for the same condition.

\section{Limitations}

We tried to conduct a comprehensive search by manually searching reference lists to find relevant search terms for remote consultation. However, there is significant variation in terminology among researchers, and this could have led to the omission of a few relevant papers. Other challenges we faced while conducting this review included the dearth of relevant papers. The included studies were conducted in 1 of 4 high-income countries. Given the growing attention on remote consultations in low- and middle-income countries [1], it is possible that relevant papers in grey literature or papers written in languages other than English exist, but were excluded due to our selection criteria. Additionally, the effect of the setting of studies is unaccounted for. For example, retail clinics differ from primary care practices, as there is less chance of establishing a long-term doctor-patient relationship. Moreover, in some studies, remote consultations were evaluated by nurse practitioners, who may have had a different skillset compared to primary care physicians who consulted with patients 
face-to-face. With the small number of studies, no clear pattern emerged in terms of the impact of setting on the outcome.

\section{Comparison With Prior Work}

Compared to face-to-face consultations, PCPs order fewer tests and investigations and are unable to physically examine patients in remote settings, which can affect the appropriateness of patient management $[8,28]$. Clinicians consulting in retail clinics via private telemedicine providers could feel pressured to prescribe antibiotics due to the expectations of patients who pay to see clinicians and the diagnostic uncertainty that stems from the lack of continuity in these commercial remote consultations [29]. On the other hand, Banks et al [30] noted that many remote consultations were followed up with face-to-face appointments for adequate clinical assessment. As antibiotic prescriptions made in follow-up appointments contribute to prescriptions made in face-to-face consultations, this could provide a partial explanation for why some of the included studies found lower antibiotic-prescribing rates in initial remote consultations and higher frequencies of follow-up consultations $[25,26]$.

However, research on the remote prescribing of antibiotics is too limited to make useful comparisons. A systematic review of reviews on the benefits of telemedicine in 2002 found too little high-quality evidence to confidently conclude that telemedicine was beneficial. However, the review reported that research was beginning to address the literature gaps in the field [31]. More recent reviews agree that there is a need for more research on the safety of care [4] and the quality and safety of prescribing through remote consultations $[4,32]$. As this is a novel study, it is difficult to compare the findings of this review directly with other reviews. We hope that this review serves as a reference point for future studies.

\section{Implication for Research and Practice}

We anticipate that remote consultations will continue to be used frequently following the COVID-19 pandemic, leading to a different mix of cases involving remote consultations compared to the mix of cases seen prior to the pandemic. Future studies should focus on conducting trials that adjust for this difference in case makeup. Moreover, the current literature is reliant on studies from high-income countries and observational studies, as confirmed by the inclusion of only one RCT in this review. Randomized trials from a variety of geographical settings are needed to achieve balance in the literature.

Antibiotic prescribing should only occur when it is safe, clinically indicated, and likely to be of benefit, regardless of consultation type [33]. Consequently, the quality and safety of antibiotic prescribing in remote consultations should be comparable to that of face-to-face consultations. Similar guideline-concordant prescribing between remote and face-to-face consultations is reassuring, but the evidence for whether the management at remote consultations is effective is less clear. Follow-up visits after remote consultations are often necessary per clinicians' advice and patients' need for physical examinations. Therefore, a high follow-up visit rate does not necessarily correlate with poor management at initial consultation, but it does raise the question of the effectiveness (including cost-effectiveness) of remote consultations. Future research investigating the resolution of symptoms as an endpoint could be beneficial.

The divided weight of evidence in this review makes it difficult to inform health policy, as the evidence regarding remote consultations is still evolving. Nonetheless, good quality evidence suggesting higher antibiotic-prescribing rate in remote consultations should not be ignored. As remote consultations are being used more frequently due to the pandemic, clear guidelines and criteria for face-to-face consultations and antibiotic management are needed. Meanwhile, PCPs should continue to be cautious when prescribing antibiotics and remain attentive to local and national guidelines. Furthermore, current antibiotic stewardship programs [34,35] could be adapted and implemented into remote care to encourage appropriate prescribing.

\section{Conclusions}

We found inconsistent evidence across the included studies for the impact of remote consulting on antibiotic prescribing in primary care. However, as the use of remote consultations continues to increase in primary care worldwide, ensuring the safety and quality of these consultations, including avoiding adverse impacts on antimicrobial resistance, should be prioritized. Studies indicating higher prescribing rates than face-to-face consulting are a concern, and PCPs should be cautious when considering prescribing antibiotics through remote consultations. Randomized trials are needed in a variety of geographical settings to inform policy on the wide-scale implementation of remote consultations. This type of research should be a priority, as long-term increases in remote consulting in primary care seems to be an inevitable consequence of the global COVID-19 pandemic.

\section{Disclaimer}

This paper presents independent research commissioned by the National Institute for Health Research under the Applied Health Research Programme for North West London. The views expressed in this publication are those of the author(s) and not necessarily those of the National Health Service, National Institute for Health Research, or Department of Health.

\section{Authors' Contributions}

SH helped with refining the research question; developed the search strings; conducted screening, critical appraisal, data extraction, and data analysis; and wrote the first draft of the manuscript. BH and GG helped with the conception and design of the review and conducted screening and critical appraisal. All authors contributed to all versions of the manuscript and approved the final submitted version. 


\section{Conflicts of Interest}

None declared.

\section{Multimedia Appendix 1}

Checklist of items to include when reporting a systematic review or meta-analysis.

[PDF File (Adobe PDF File), 52 KB-Multimedia Appendix 1]

\section{Multimedia Appendix 2}

Search terms and strategy for each electronic database.

[PDF File (Adobe PDF File), 98 KB-Multimedia Appendix 2]

\section{Multimedia Appendix 3}

Quality assessment for observational studies and randomized trials.

[PDF File (Adobe PDF File), 70 KB-Multimedia Appendix 3]

\section{References}

1. World Health Organization. In: World Health Organization, editor. Global diffusion of eHealth: making universal health coverage achievable: report of the third global survey on eHealth. Geneva, Switzerland: WHO Document Production Services; Dec 15, 2016.

2. Majeed A, Maile EJ, Bindman AB. The primary care response to COVID-19 in England's National Health Service. J R Soc Med 2020 Jun;113(6):208-210. [doi: 10.1177/0141076820931452] [Medline: 32521196]

3. Alwashmi MF. The Use of Digital Health in the Detection and Management of COVID-19. Int J Environ Res Public Health 2020 Apr 23;17(8):2906 [FREE Full text] [doi: 10.3390/ijerph17082906] [Medline: $\underline{\text { 32340107] }}$

4. Mold F, Hendy J, Lai Y, de Lusignan S. Electronic Consultation in Primary Care Between Providers and Patients: Systematic Review. JMIR Med Inform 2019 Dec 03;7(4):e13042 [FREE Full text] [doi: 10.2196/13042] [Medline: $\underline{31793888]}$

5. Armfield NR, Gray LC, Smith AC. Clinical use of Skype: a review of the evidence base. J Telemed Telecare 2012 Apr;18(3):125-127. [doi: 10.1258/jtt.2012.SFT101] [Medline: 22362829]

6. Haaijer-Ruskamp FM, Stewart R, Wesseling H. Does indirect consultation lead to overprescribing in general practice? Soc Sci Med 1987;25(1):43-46. [doi: 10.1016/0277-9536(87)90205-x] [Medline: $\underline{3616696}$ ]

7. Sundseth AC, Gjelstad S, Straand J, Rosvold EO. General practitioners' prescriptions of benzodiazepines, Z-hypnotics and opioid analgesics for elderly patients during direct and indirect contacts. A cross-sectional, observational study. Scand J Prim Health Care 2018 Jun;36(2):115-122 [FREE Full text] [doi: 10.1080/02813432.2018.1459164] [Medline: 29656692]

8. Hayhoe B, Greenfield G, Majeed A. Is it getting easier to obtain antibiotics in the UK? Br J Gen Pract 2019 Feb;69(679):54-55. [doi: 10.3399/bjgp19X700829] [Medline: $\underline{30704991]}$

9. Hay AD. Antibiotic prescribing in primary care. BMJ 2019 Feb 27;364:1780. [doi: 10.1136/bmj.1780] [Medline: $\underline{30814116]}$

10. Llor C, Bjerrum L. Antimicrobial resistance: risk associated with antibiotic overuse and initiatives to reduce the problem. Ther Adv Drug Saf 2014 Dec;5(6):229-241 [FREE Full text] [doi: 10.1177/2042098614554919] [Medline: 25436105]

11. Interagency Coordination Group on Antimicrobial Resistance. No Time To Wait: Securing the Future From Drug-Resistant Infections. Report to the Secretar-General of the United Nations. World Health Organization. 2019 Apr. URL: https://www. who.int/docs/default-source/documents/no-time-to-wait-securing-the-future-from-drug-resistant-infections-en. pdf?sfvrsn=5b424d7 6 [accessed 2020-10-21]

12. Liberati A, Altman DG, Tetzlaff J, Mulrow C, Gøtzsche PC, Ioannidis JPA, et al. The PRISMA statement for reporting systematic reviews and meta-analyses of studies that evaluate health care interventions: explanation and elaboration. J Clin Epidemiol 2009 Oct;62(10):e1-34 [FREE Full text] [doi: 10.1016/j.jclinepi.2009.06.006] [Medline: 19631507]

13. National Heart, Lung, and Blood Institute. Quality Assessment Tool for Observational Cohort and Cross-Sectional Studies. Study Quality Assessment Tools. URL: https://www.nhlbi.nih.gov/health-topics/study-quality-assessment-tools [accessed 2020-10-21]

14. Higgins JPT, Altman DG, Gøtzsche PC, Jüni P, Moher D, Oxman AD, Cochrane Bias Methods Group, Cochrane Statistical Methods Group. The Cochrane Collaboration's tool for assessing risk of bias in randomised trials. BMJ 2011 Oct 18;343:d5928 [FREE Full text] [doi: 10.1136/bmj.d5928] [Medline: 22008217]

15. Popay J, Arai L, Britten N, Petticrew M, Rodgers M, Sowden A, et al. Guidance on the conduct of narrative synthesis in systematic reviews: A product from the ESRC Methods Programme. ResearchGate.: Lancaster University URL: https:/ /tinyurl.com/y6regpvh [accessed 2020-10-21]

16. Huibers L, Moth G, Christensen MB, Vedsted P. Antibiotic prescribing patterns in out-of-hours primary care: a population-based descriptive study. Scand J Prim Health Care 2014 Dec;32(4):200-207 [FREE Full text] [doi: 10.3109/02813432.2014.972067] [Medline: 25350313] 
17. Christensen MB, Nørøxe KB, Moth G, Vedsted P, Huibers L. Drug prescriptions in Danish out-of-hours primary care: a 1-yearpopulation-based study. Scand J Prim Health Care 2016 Dec;34(4):453-458 [FREE Full text] [doi: 10.1080/02813432.2016.1248622] [Medline: 27804314]

18. Murray MA, Penza KS, Myers JF, Furst JW, Pecina JL. Comparison of eVisit Management of Urinary Symptoms and Urinary Tract Infections with Standard Care. Telemed J E Health 2020 May;26(5):639-644. [doi: 10.1089/tmj.2019.0044] [Medline: $\underline{31313978]}$

19. Penza KS, Murray MA, Myers JF, Maxson J, Furst JW, Pecina JL. Treating pediatric conjunctivitis without an exam: An evaluation of outcomes and antibiotic usage. J Telemed Telecare 2020;26(1-2):73-78. [doi: 10.1177/1357633X18793031] [Medline: $\underline{30153768]}$

20. Rokstad K, Straand J. Drug prescribing during direct and indirect contacts with patients in general practice: a report from the Møre \& Romsdal Prescription Study. Scand J Prim Health Care 1997 Jun;15(2):103-108. [doi: 10.3109/02813439709018496] [Medline: 9232712]

21. McKinstry B, Walker J, Campbell C, Heaney D, Wyke S. Telephone consultations to manage requests for same-day appointments: a randomised controlled trial in two practices. Br J Gen Pract 2002 Apr;52(477):306-310. [Medline: 11942448]

22. Mehrotra A, Paone S, Martich GD, Albert SM, Shevchik GJ. A comparison of care at e-visits and physician office visits for sinusitis and urinary tract infection. JAMA Intern Med 2013 Jan 14;173(1):72-74 [FREE Full text] [doi:

10.1001/2013.jamainternmed.305] [Medline: 23403816]

23. Ewen E, Willey VJ, Kolm P, McGhan WF, Drees M. Antibiotic prescribing by telephone in primary care. Pharmacoepidemiol Drug Saf 2015 Feb;24(2):113-120. [doi: 10.1002/pds.3686] [Medline: 25079292]

24. Uscher-Pines L, Mulcahy A, Cowling D, Hunter G, Burns R, Mehrotra A. Access and Quality of Care in Direct-to-Consumer Telemedicine. Telemed J E Health 2016 Apr;22(4):282-287 [FREE Full text] [doi: 10.1089/tmj.2015.0079] [Medline: 26488151]

25. Shi Z, Mehrotra A, Gidengil CA, Poon SJ, Uscher-Pines L, Ray KN. Quality Of Care For Acute Respiratory Infections During Direct-To-Consumer Telemedicine Visits For Adults. Health Aff (Millwood) 2018 Dec;37(12):2014-2023 [FREE Full text] [doi: 10.1377/hlthaff.2018.05091] [Medline: 30633682]

26. Johnson KM, Dumkow LE, Burns KW, Yee MA, Egwuatu NE. Comparison of Diagnosis and Prescribing Practices Between Virtual Visits and Office Visits for Adults Diagnosed With Sinusitis Within a Primary Care Network. Open Forum Infect Dis 2019 Sep;6(9):ofz393 [FREE Full text] [doi: 10.1093/ofid/ofz393] [Medline: 31660415]

27. Ray KN, Shi Z, Gidengil CA, Poon SJ, Uscher-Pines L, Mehrotra A. Antibiotic Prescribing During Pediatric Direct-to-Consumer Telemedicine Visits. Pediatrics 2019 May;143(5):e20182491. [doi: 10.1542/peds.2018-2491] [Medline: 30962253]

28. Wallace P, Haines A, Harrison R, Barber J, Thompson S, Jacklin P, Virtual Outreach Project Group. Joint teleconsultations (virtual outreach) versus standard outpatient appointments for patients referred by their general practitioner for a specialist opinion: a randomised trial. Lancet 2002 Jun 08;359(9322):1961-1968. [doi: 10.1016/s0140-6736(02)08828-1] [Medline: $\underline{12076550]}$

29. DeJong C, Santa J, Dudley RA. Websites that offer care over the Internet: is there an access quality tradeoff? JAMA 2014 Apr 02;311(13):1287-1288. [doi: 10.1001/jama.2014.1026] [Medline: 24691602]

30. Banks J, Farr M, Salisbury C, Bernard E, Northstone K, Edwards H, et al. Use of an electronic consultation system in primary care: a qualitative interview study. Br J Gen Pract 2018 Jan;68(666):e1-e8. [doi: 10.3399/bjgp17X693509] [Medline: 29109115]

31. Ekeland AG, Bowes A, Flottorp S. Effectiveness of telemedicine: a systematic review of reviews. Int J Med Inform 2010 Nov;79(11):736-771. [doi: 10.1016/j.ijmedinf.2010.08.006] [Medline: 20884286]

32. McLean S, Sheikh A, Cresswell K, Nurmatov U, Mukherjee M, Hemmi A, et al. The impact of telehealthcare on the quality and safety of care: a systematic overview. PLoS One 2013;8(8):e71238 [FREE Full text] [doi: 10.1371/journal.pone.0071238] [Medline: 23977001]

33. Remote prescribing high level principles Internet. General Medical Council. URL: https://www.gmc-uk.org/ethical-guidance/ learning-materials/remote-prescribing-high-level-principles [accessed 2020-10-21]

34. TARGET Antibiotics Toolkit Internet. Royal College of General Practitioners. URL: https://www.rcgp.org.uk/targetantibiotics [accessed 2020-10-21]

35. Choosing Wisely: Promoting conversations between providers and patients. American Board of Internal Medicine Foundation. URL: https://www.choosingwisely.org/ [accessed 2020-10-21]
Abbreviations
PCP: primary care professionals
RCT: randomized controlled trial
UTI: urinary tract infection 
Edited by G Eysenbach; submitted 14.08.20; peer-reviewed by J Pecina, T Schopf; comments to author 11.09.20; revised version received 01.10.20; accepted 02.10.20; published 09.11.20

Please cite as:

Han SM, Greenfield G, Majeed A, Hayhoe B

Impact of Remote Consultations on Antibiotic Prescribing in Primary Health Care: Systematic Review

J Med Internet Res 2020;22(11):e23482

URL: http://www.jmir.org/2020/11/e23482/

doi: $10.2196 / 23482$

PMID: 33031045

(CSeung Min Han, Geva Greenfield, Azeem Majeed, Benedict Hayhoe. Originally published in the Journal of Medical Internet Research (http://www.jmir.org), 09.11.2020. This is an open-access article distributed under the terms of the Creative Commons Attribution License (https://creativecommons.org/licenses/by/4.0/), which permits unrestricted use, distribution, and reproduction in any medium, provided the original work, first published in the Journal of Medical Internet Research, is properly cited. The complete bibliographic information, a link to the original publication on http://www.jmir.org/, as well as this copyright and license information must be included. 